\title{
(RE)PENSAR O ENSINO E APRENDIZAGEM DA REPRESENTAÇÃO DA INFORMAÇÃO E DO CONHECIMENTO
}

\author{
RETHINKING ABOUT THE TEACHING AND LEARNING \\ PROCESS IN THE REPRESENTATION OF \\ INFORMATION AND KNOWLEDGE
}

Ana Maria Pereiraa

\begin{abstract}
RESUMO
Introdução: O presente artigo propôs-se a (re)pensar o ensino e a aprendizagem da representação da informação e do conhecimento em tempos de reaprendizagem. Objetivo: Identificar como ocorre o ensino e a aprendizagem da representação da informação e do conhecimento. Metodologia: a pesquisa realizada é de abordagem qualitativa, descritiva, do tipo levantamento bibliográfico. Para a coleta de dados, foi feito um questionário encaminhado aos docentes e discentes do curso de Biblioteconomia e Gestão da Informação da UDESC via grupos de WhatsApp. O questionário foi respondido por escrito por alguns e por gravação de voz por outros respondentes, bem como por e-mail por um respondente. Para o tratamento dos dados, foi realizada a transcrição das entrevistas por áudio, encaminhada aos entrevistados para conferência e autorização para publicação. Para análise dos dados, foi realizada a categorização por assunto, e análise de conteúdo. Resultados: Como resultado, compreende-se que o retorno dos questionários não foi representativo para a demanda de docentes e dos discentes do Curso, no entanto, considera-se que refletem o momento atual da educação no Brasil. Conclusões: como conclusão, identificou-se que os docentes e discentes estão trabalhando juntos nesse novo formato de ensino remoto, partilhando as dificuldades com as tecnologias, e com o próprio modelo de ensino e aprendizagem que está sendo repensado, reaprendendo juntos.
\end{abstract}

Descritores: Representação da informação. Representação do conhecimento. Ensino e aprendizagem. Reaprendizagem.

\section{INTRODUÇÃO}

"A educação é um ato de amor, por isso, um ato de coragem. Não pode temer o debate. A análise da realidade. Não pode fugir

a Doutora em Tecnologias e Sistemas de Informação pela Universidade do Minho, Portugal. Professora do Programa de Pós-Graduação em Gestão da Informação da Universidade do Estado de Santa Catarina (UDESC). E-mail: ana.pereira@udesc.br 
à discussão criadora, sob pena de ser uma farsa.". (FREIRE, 1999, p. 97)

Ao iniciar a escrita desse artigo, muitos pensamentos vieram sobre um tema aparentemente tão simples, mas altamente complexo. Dois focos que podem ser agrupados: representação da informação e do conhecimento e os novos tempos de reaprendizagem.

Foi necessário recorrer ao levantamento bibliográfico, à revisão de literatura, a questionários com colegas de Departamento e aos acadêmicos (que se dispuseram a responder), sobre os temas, visto que nada apresentava uma abordagem tão concreta e simples sobre os focos de estudo.

Nessa busca incessante, chegou-se ao nosso Patrono Brasileiro da Educação, Paulo Freire, a quem dedico a epígrafe desse artigo, que muito nos ensinou e continua tão atual no contexto da sociedade nacional e, talvez, mundial. Não se tem aqui a pretensão de aprofundar-se em questões sociológicas e políticas sobre a educação no Brasil, tão bem trabalhadas por Freire, mas clarificar que Freire, em pelo século XXI, nunca esteve tão atual.

No entanto, como foco é a (re)aprendizagem, Paulo Freire é, indiscutivelmente, atual em nossa sociedade brasileira. Para Freire, a aprendizagem deve ser centrada no educando, com o educando, sendo o educador o mediador desse processo.

O processo de aprendizagem tradicional na sociedade brasileira sempre esteve centrada nas normas, e imposta do superior para o inferior, ou seja, as Instituições superiores apresentam e determinam como será realizado o processo educacional, baseado nas atuações mercadológicas da educação privada, voltada para uma elite dominante.

O educando recebe o material sem questionar, sem entender o porquê de tantas regras, o ensino tornou-se foco de preparação somente para o vestibular, não como aprendizagem para uma consciência crítica e auto crítica.

Os educandos chegam ao ensino superior com dificuldades de desenvolver a consciência crítica, acostumados a receber sem questionar, e quando questionam, muitas vezes, são ignorados em suas falas e pensamentos. E assim, estava a sociedade nesse processo, quieta, fingindo que tudo estava bem, do jeito que estava. De repente tudo muda, e passa a uma transitoriedade em que 
ninguém pode mais ignorar, passa-se a questionar, a temer, a exigir mudanças: pais estão em casa com filhos (em uma convivência há muito esquecida por muitas famílias), a educação volta a sua fase natural (começa em casa), um processo natural em que os lares refletem a sociedade em que vivemos.

Tempos pandêmicos, em que não há certezas, somente duvidas, e com as dúvidas ocorre o despertar da consciência, a necessidade de criticidade, e a educação tornou-se o foco central dessa consciência com informações contraditórias sobre um vírus (COVID 19) que traz mais questionamentos que respostas, que desafia a ciência, a medicina, os governos, a sociedade e, claro, a educação.

Neste momento de transformação do pensar, repensar, aprender e reaprender, de forma cíclica, ainda "tateando" no que pode e não pode, no certo e errado, o ensino e aprendizagem nas instituições de ensino brasileira tem que se reinventar.

Nesse novo contexto, o processo de ensino e aprendizagem que antes no Brasil era realizado tradicionalmente, de forma presencial, passou a ser remoto, e à distância, abrindo espaço para a desigualdade social, desde sempre ignorada na sociedade brasileira, pois se verifica que a ala da sociedade elitizada e mercadológica defende a educação a distância como solução para todos os problemas da educação no Brasil; como se fosse a solução.

Poderia ser, se fosse uma sociedade igualitária como a defendida por Freire, com uma educação participativa e democrática, em que TODOS e TODAS tivessem acesso à educação, às tecnologias de comunicação e informação (TIC), à internet com banda larga de qualidade, computadores compatíveis em suas casas, smartphones, tablets e infraestrutura em home office para realizar as aulas, o que, infelizmente, não acontece. Outra necessidade seria que os pais e mães (primeiros educadores) tivessem condições de auxiliar seus filhos e filhas no processo de aprendizagem, o que, infelizmente, para a maioria dos pais e mães, não é possível.

Por falar em educadores, há que se considerar os professores, que abrangem desde o ensino infantil ao nível superior, desvalorizados, cansados, doentes física e emocionalmente, muitos sem condições de infraestrutura para 
ministrar suas aulas em home office, se reinventando e reaprendendo a ser professor em seu fazer diário, às custas de sacrifícios que a mídia transforma em shows de "super heróis" como se fosse o mais normal do mundo.

Esses e outros aspectos têm sido colocados em discussão por meio das redes sociais, num grito quase ensurdecedor que a sociedade, muitas vezes, se faz de surda para não ouvir, pois só se ouve o que interessa.

Essas reflexões não são de um filósofo, nem pedagogo, mas de uma docente, que, durante esses novos tempos, buscou aprender e reaprender a ser professora, juntando-se a um coro ensurdecedor e não ouvido da sociedade educacional em seu fazer diário do processo de ensino e aprendizagem.

$\mathrm{E}$, assim, do ponto de vista da (re)aprendizagem, considera-se altamente complexo a discussão desse tema aqui apresentado, e não há a pretensão de abordar exaustivamente o conceito de aprendizagem. No entanto, com uma abordagem Freiriana, apresenta-se o conceito de aprendizagem que se acredita estar coerente com o momento de auto aprendizagem necessário nesse contexto pandêmico.

Para Freire (1996, p.15)

[...] nas condições de verdadeira aprendizagem os educandos vão se transformando em reais sujeitos da construção e da reconstrução do saber ensinado, ao lado do educador, igualmente sujeito do processo. Só assim podemos falar realmente de saber ensinado, em que o objeto ensinado é apreendido na sua razão de ser e, portanto, aprendido pelos educandos.

A aprendizagem pode ser compreendida como a capacidade que cada ser humano tem de compreender e apreender sua realidade de acordo com suas experiências e práxis, de transformar-se, e de transformar a realidade em que vive.

Segundo Freire (2001, p. 264)

Por isso também é que ensinar não pode ser um puro processo, como tanto tenho dito, de transferência de conhecimento do ensinante ao aprendiz. Transferência mecânica de que resulte a memorização maquinal que já critiquei. Ao estudo crítico corresponde um ensino igualmente crítico que demanda necessariamente uma forma crítica de compreender e de realizar a leitura da palavra e a leitura do mundo, leitura do contexto.

Como aborda Freire (2001), é preciso que o processo de ensino e aprendizagem contribua para o transformar crítico do educando, e o ensino, 
remoto ou online, deve proporcionar esse ato transformador em que os sujeitos (educandos) "[...] vão se transformando em reais sujeitos da construção e da reconstrução do saber ensinado, ao lado do educador, igualmente sujeito do processo.". (FREIRE, 2001, p.15).

Essa transformação passa pelo processo cognitivo de interpretação da realidade, de maturação da informação para novas construções de conhecimentos. Nesse repensar, vem a questão: o que mudou nesse processo, no contexto atual voltado para o ensino das disciplinas na área de Organização e Representação da informação e do conhecimento por meio do uso das TIC com o ensino remoto?

\section{EDUCAÇÃO E TECNOLOGIAS: UMA PARCERIA EM EVOLUÇÃO}

O conhecimento nos é transmitido por intermédio de um mediador que nos informa sobre a realidade e sua interpretação. O mediador pode nos transmitir seus conhecimentos de diversas formas: oral, escrita, pictórica, visual, áudio, via satélite etc. (PEREIRA, 2000).

$O$ ensino e aprendizagem que se utilizam da informação e do conhecimento registrados, atualmente, deixaram os espaços de aprendizagem tradicionais denominados salas de aula para se inserirem em novos espaços, remotos e virtuais para a arte do ensino e aprendizagem, se utilizando de novas ferramentas de ensino nos mais diversos formatos tais como vídeos, lives, podcasts, webinars, Web com plataforma, Redes sociais, Blogs, Webquest, ferramentas online, TV pendrive, Smart TV, Wikis, E-mail, Comunicadores, Produção audiovisual, Fotolog, Processador de textos e Jogos, plataformas institucionais e outras formas.

O conteúdo, nesse novo contexto do ambiente educacional, traz grandes transformações no processo de ensino e aprendizagem de forma interativa, gerando novos paradigmas que trazem a inconstância e a insegurança tanto para o aprendiz quanto para o educador, visto que a sociedade brasileira ainda não tem uma cultura de educação a distância, nem nossas instituições escolares possuem infraestrutura para atender a essa demanda.

A educação e os educadores têm se reinventado para transformar 0 
ensino presencial em remoto e/ou virtual e a distância, se utilizando de didática, técnicas de ensino e aprendizagem e tecnologias para disponibilizar aos educandos o melhor conteúdo em seus mais diversos formatos.

Os termos educação a distância, educação on-line e e-learning muitas vezes são considerados correspondentes, mas segundo Almeida (2003, p. 332) são diferentes entre si.

A educação a distância pode se realizar pelo uso de diferentes meios (correspondência postal ou eletrônica, rádio, televisão, telefone, fax, computador, internet, etc.), técnicas que possibilitem a comunicação e abordagens educacionais; baseiase tanto na noção de distância física entre o aluno e o professor como na flexibilidade do tempo e na localização do aluno em qualquer espaço.

Importante destacar que no Brasil, até o momento, a educação a distância era voltada somente para o público adulto.

Educação on-line é uma modalidade de educação a distância realizada via internet, cuja comunicação ocorre de forma sincrônicas ou assincrônicas. Tanto pode utilizar a internet para distribuir rapidamente as informações como pode fazer uso da interatividade propiciada pela internet para concretizar a interação entre as pessoas, cuja comunicação pode se dar de acordo com distintas modalidades comunicativas, a saber:

- comunicação um a um, ou dito de outra forma, comunicação entre uma e outra pessoa, como é o caso da comunicação via e-mail, que pode ter uma mensagem enviada para muitas pessoas desde que exista uma lista específica para tal fim, mas sua concepção é a mesma da correspondência tradicional, portanto, existe uma pessoa que remete a informação e outra que a recebe;

- comunicação de um para muitos, ou seja, de uma pessoa para muitas pessoas, como ocorre no uso de fóruns de discussão, nos quais existe um mediador e todos que têm acesso ao fórum, enxergam as intervenções e fazem suas intervenções;

- comunicação de muitas pessoas para muitas pessoas, ou comunicação estelar, que pode ocorrer na construção colaborativa de um site ou na criação de um grupo virtual, como é o caso das comunidades colaborativas em que todos participam da criação e desenvolvimento da própria comunidade e respectivas produções. (ALMEIDA, 2003, p.332).

A educação on-line definida por Almeida (2003), também conhecida por educação remota, tem sido utilizada nesse momento em todo Brasil, com o objetivo de proporcionar aos educandos a continuidade do processo de ensino 
e aprendizagem, interrompido pela pandemia.

O e-Learning é uma modalidade de educação a distância com suporte na internet que se desenvolveu a partir de necessidades de empresas relacionadas com 0 treinamento de seus funcionários, cujas práticas estão centradas na seleção, organização e disponibilização de recursos didáticos hipermediáticos. (ALMEIDA, 2003, p. 333)

A autora tem tecido várias críticas sobre esse tipo de educação, visto que há um baixo aproveitamento da aprendizagem por parte da interatividade com as TIC, desmotivação, entre outras reclamações dos profissionais. Segundo Almeida (2003, p. 333) a tendência é que "o e-Learning está sendo apontado como a tendência atual de treinamento, aprendizagem e formação continuada no setor empresarial.".

Esclarecido a diferença entre os temos sobre a educação e o uso das TIC, verificamos que, de acordo com Bruzzi (2016, p. 477),

[...] a educação vive às voltas com as tecnologias desde 1650. Com aparatos como o Horn-Book (tratava-se de uma madeira com impressos), utilizado para alfabetização de crianças e textos religiosos (era uma forma na época colonial de ajudar as crianças a aprender a ler e escrever). Entre 1850 a 1870 tivemos outro aparato curioso: o Ferule (tratava-se de uma espécie de espeto de madeira mais grosso, que servia como apontador/indicador). Tanto o Ferule (figura 2), como o HornBook (figura 1), tinham dupla aplicação, serviam tanto para aprendizagem como para castigo físico imputado á alunos dispersos e/ou que não conseguiam aprender as lições. O que reforçava a ideia de uma educação punitiva (não muito distante dos dias atuais, se compararmos os modelos de avaliação atuais com as punições físicas citadas).

Figura 1 - Horn-book

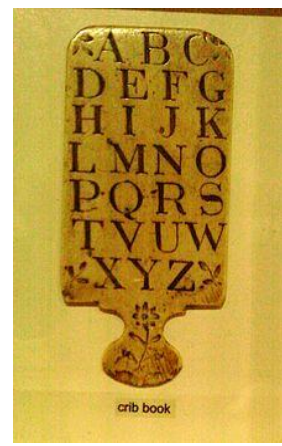

Figura 2 - Ferule

Fonte: Keith Lyons, (2020). Disponível em: https://keithlyons.me/ferule/

Fonte: Wikipedia (2020). Disponível em:

https://en.wikipedia.org/wiki/Hornbook

A partir das TIC apresentadas por Bruzzi (2016), foi realizada uma 
pesquisa para identificar quais as principais tecnologias utilizadas na educação, no entanto, as datas apresentadas estão de acordo com seus surgimentos, não necessariamente quando foi iniciado seu uso, principalmente as mais recentes, visto que não há consenso entre seus autores do surgimento dessas tecnologias, nem mesmo o seu uso no processo de ensino e aprendizagem.

Nesse repensar da evolução do uso das tecnologias pela educação com vistas a melhoria do processo de ensino e aprendizagem, é difícil identificar quando, exatamente, tais ferramentas foram inseridas nesse processo, bem como o que são consideradas tecnologias para os estudiosos e pesquisadores da área. Se considerar que o ser humano desde sempre registrou seus conhecimentos por meio das pinturas rupestres, utilizando o carbonato de calcário (giz), as paredes das cavernas como "quadros para escrever, desenhar", e que de certa forma pode ser visto como tecnologia da época, então desde sempre as tecnologias acompanham a evolução educacional do ser humano.

Outro exemplo foi a técnica encáustica criada pelos egípcios, gregos e romanos por volta de 2000 A.C para fazer seus registros, utilizando uma mistura de cera de abelha e alguns pigmentos para realizar suas pinturas.

Nota-se que a linha de evolução deixa a data em aberto a partir de 2011, por não identificar as datas de tecnologias e aplicativos desenvolvidos a partir desse período. Identificou-se que há uma progressiva e rápida evolução dessas tecnologias, mas sem uma data definida de cada uma, que foram evoluindo de acordo com as necessidades da humanidade. Assim, fica em aberto para que as novas TIC e aplicativos que estão surgindo possam ser incorporados, pois não se tem a pretensão de esgotar essa linha evolucionária.

Não é objetivo desse artigo discorrer sobre cada tipo de tecnologia ou aplicativo apresentado, visto não ser este o foco, mas, a partir dessas tecnologias, compreender como ocorre o ensino da representação do conhecimento e da informação nesse novo contexto educacional, em tempos de repensar e re(aprender) o processo de ensino e aprendizagem.

Ao realizar uma breve revisão de literatura sobre o uso das tecnologias de comunicação e informação (TIC) e os aplicativos usados na educação elaborouse uma linha do tempo, quadro 1, para identificar sua evolução até o momento. 
Quadro 1: Linha do Tempo - Evolução das Tecnologias de Informação e Comunicação e aplicativos na Educação

\begin{tabular}{|c|c|c|c|c|c|c|}
\hline 40.000 A.C & 30.000 A.C & 20000 A.C & 3000 A.C & 1650 & 1800 & 1850 a 1870 \\
\hline $\begin{array}{l}\text { Giz (Carbonato de } \\
\text { cálcio) } \\
\text { Pintura Rupestres }\end{array}$ & Pintura Rupestre & $\begin{array}{l}\text { Escrita } \\
\text { Cuneiforme } \\
\text { (em argila) }\end{array}$ & $\begin{array}{l}\text { Técnica } \\
\text { Encáustica } \\
\text { (egípcios, gregos } \\
\text { e romanos) }\end{array}$ & Horn-Book & $\begin{array}{l}\text { Lousa (quadro de } \\
\text { ardósia }- \text { James } \\
\text { Pillan) }\end{array}$ & $\begin{array}{l}\text { Ferule } \\
\text { Magic Lantern }\end{array}$ \\
\hline 1889 & 1890 & 1900 & 1905 & 1920 & 1925 & 1930 \\
\hline Cinetoscópio & $\begin{array}{l}\text { School Slate } \\
\text { Chalkboard }\end{array}$ & Lápis & Estereoscopio & $\begin{array}{l}\text { Datilógrafo } \\
\text { (máquina } \\
\text { escrever) }\end{array}$ & $\begin{array}{l}\text { Film Projector } \\
\text { Rádio }\end{array}$ & Retroprojetor \\
\hline 1935 & 1939 & 1940 & 1945 & 1951 & 1957 & 1958 \\
\hline $\begin{array}{l}\text { Gravações } \\
\text { Fonográficas }\end{array}$ & Televisão & $\begin{array}{l}\text { Caneta } \\
\text { esferográfica } \\
\text { Mimeografo }\end{array}$ & $\begin{array}{l}\text { Hipertexto } \\
\text { Memex (Vanevar } \\
\text { Bush) }\end{array}$ & $\begin{array}{l}\text { Videotapes } \\
\text { Cassetes de video }\end{array}$ & $\begin{array}{ll}\text { Acelerador } & \text { de } \\
\text { Leitura } & \\
\text { Máquina de } & \\
\text { Aprendizagem } & \text { de } \\
\text { Skinner } & \\
\end{array}$ & Televisão Educativa \\
\hline 1959 & 1960 & 1965 & 1970 & 1972 & 1980 & 1985 \\
\hline Fotocopiadora & $\begin{array}{ll}\text { Liquid Paper } & \\
\text { Introdução } & \text { do } \\
\text { computador } & \text { ao } \\
\text { ensino } & \end{array}$ & Microfilm & $\begin{array}{l}\text { Calculadora } \\
\text { Manual } \\
\text { Disquetes } \\
\text { Discos duros }\end{array}$ & Cartão Perfurado & $\begin{array}{l}\text { Computador } \\
\text { pessoal } \\
\text { Computador } \\
\text { mesa }\end{array}$ & CD ROOM \\
\hline 1990-1991 & 1994 & 1999 & 2003 & 2004 & 2005 & 2006 \\
\hline $\begin{array}{l}\text { Hipertexto } \\
\text { Hipermidia } \\
\text { Computadores } \\
\text { portáteis } \\
\text { Wiki }\end{array}$ & $\begin{array}{l}\text { Blog (Open Diary - } \\
\text { Claudio Pinhanez) } \\
\text { Internet nas } \\
\text { Universidades }\end{array}$ & $\begin{array}{l}\text { Quadro } \\
\text { Interativo } \\
\text { Lousa Digital } \\
\text { Plataforma } \\
\text { Moodle }\end{array}$ & $\begin{array}{lrr}\begin{array}{l}\text { Surgem as } \\
\text { sociais }\end{array} \text { redes } & \text { My } \\
\text { Space } & & \\
\text { Linkedln } & & \end{array}$ & $\begin{array}{l}\text { Orkut } \\
\text { Flickr } \\
\text { Facebook } \\
\text { Podcast }\end{array}$ & $\begin{array}{l}\text { Web } 2.0 \\
\text { Youtube }\end{array}$ & $\begin{array}{l}\text { O Computador por } \\
\text { aluno - UCA } \\
\text { Twitter }\end{array}$ \\
\hline 2000 a 2008 & 2008 a 2009 & 2009 & 2010 & $2011-$ & & \\
\hline $\begin{array}{l}\text { Multimidia e e } \\
\text { comunicação com } \\
\text { câmeras }\end{array}$ & Videoconferências & $\begin{array}{l}\text { Aplicativo } \\
\text { WhatsApp } \\
\text { Instagram }\end{array}$ & $\begin{array}{l}\text { Tablets } \\
\text { Smartphone } \\
\text { (ensino) }\end{array}$ & $\begin{array}{l}\text { Webinar } \\
\text { Webcast } \\
\text { Streaming de Midia } \\
\text { Lives }\end{array}$ & & \\
\hline
\end{tabular}

Fonte: Autora (2020). 
Nessa linha, estão representadas como Novas Tecnologias de Informação e Comunicação (NTIC), classificadas em dois grandes grupos por Vallejo (2007, p. 28-29):

- Básicas: São aquelas que funcionam por si mesmas e, ao mesmo tempo, fazem que funcione outro tipo de tecnologia. Encontramos neste grupo o computador, o vídeo, o televisor, o telefone móvel, a fotografia digital e o CD/DVD.

- Baseadas em outras tecnologias: Esse grupo não tem autonomia, funcionando com dependência de outras tecnologias. Basicamente se enquadram aqui as redes telemáticas, a videoconferência e os videojogos.

Não estão apresentadas nessa linha evolutiva o processo de escrita que se utiliza de tecnologias desde a antiguidade até atualidade, em crescente expansão, dos tabletes de argila até o tablet, perpassando pelas modernas plataformas de formatação de textos (como o Word, por exemplo).

Ao pensar nesse processo de evolução das TIC e seu uso na educação, trouxe novas inquietações sobre o ensino da representação da informação e do conhecimento na área da Biblioteconomia, inquietações que partiram do momento pandêmico, em que o ensino presencial deixou de ser realizado, dando lugar ao ensino on-line ou remoto, de acordo com as definições e diferenciações estabelecidas por Almeida (2003).

\section{REPRESENTAÇÃO DA INFORMAÇÃO E DO CONHECIMENTO}

No momento, encontramo-nos em outro nível de representação: a representação da realidade que interfere diretamente no novo fazer do educador, considerado como mediador do processo de ensino e aprendizagem. De acordo com Arruda e Chagas (2002, p.182 apud LANCASTER, 1993, p. 306) a representação pode ser considerada como "Um registro que se destina a indicar quais assuntos que são tratados num item bibliográfico. Um resumo é uma forma de representação; outra é o conjunto de termos de indexação.".

Os autores se referem à representação de item bibliográfico, ainda no formato tradicional (o livro, o artigo de periódico, as fichas de anotações e tantos outros tipos de documentos). A preocupação, nesse contexto, está focada em 
representar o conteúdo informacional do item bibliográfico, bem como representá-lo fisicamente, destacando-o como uma nova fonte de informação que possibilita ao usuário identificar o item bibliográfico de forma simples e rápida, de acordo com sua necessidade informacional.

De acordo com Furetiere apud Chartier (1991, p. 13)

Nas definições antigas (por exemplo, a do Dicionário universal de Furetière em sua edição de 1727), as acepções correspondentes à palavra "representação" atestam duas famílias de sentido aparentemente contraditórias: por um lado, a representação faz ver uma ausência, o que supõe uma distinção clara entre o que representa e o que é representado; de outro, é a apresentação de uma presença, a apresentação pública de uma coisa ou de uma pessoa. Na primeira acepção, a representação é o instrumento de um conhecimento mediato que faz ver um objeto ausente substituindo-lhe uma "imagem" capaz de repô-lo em memória e de "pintá-lo" tal como é.

$\mathrm{Na}$ definição de Furetiere e Chartier (1991), os autores descrevem a palavra representação e apresentam sua face contraditória: a ausência e a presença do que é representado. Representar, na concepção dos autores, interfere diretamente no item ou objeto que é representado. E representar um item bibliográfico significa identificar nesse contexto o objeto e os instrumentos que são utilizados para representá-lo.

Não temos o objetivo de iniciar uma discussão sobre o que é representar, no entanto, foi necessário identificar o que autores como Fretiere e Chartier abordaram na literatura sobre a representação. Os autores têm o foco na leitura para a representação e sua importância sobre sua interpretação.

No entanto, Lara (1993, p. 223) afirma que:

A representação da informação resulta de um conjunto de procedimentos denominado Análise Documentária, cuja metodologia permite expressar o conteúdo dos documentos sob formas distintas, facilitando assim a sua recuperação (GARDIN apud CUNHA, 1990, p. 59). Um dos instrumentos utilizados pela $A D$ é a $L D$ que tem por função, a normalização das unidades significantes ou conceituais presentes no texto original como meio de viabilizar sua comunicação. Ao transformar a informação presente nos textos em linguagem natural e/ou especializada para uma LD controlada, a AD opera com a significação, isto é, procura representar adequadamente as informações sem comprometer o seu significado. 
De certa forma, a definição de representação de Lara (2003) está coerente com a visão de Chartier (1991, p.11)

[...] o texto existe em si, separado de toda materialidade, é preciso lembrar que não há texto fora do suporte que lhe permite ser lido (ou ouvido) e que não há compreensão de um escrito, qualquer que seja, que não dependa das formas pelas quais atinge o leitor.

Ao realizar uma analogia com o processo de ensino e aprendizagem e a visão de representação de Chartier (1991), é compreensível que esse processo só ocorre quando há a interpretação criativa e crítica da informação e do conhecimento registrado, visto que, sem essa interpretação, o educando tornase um ser apático, desinteressado em aprender e, consequentemente, o educador (aqui mediador) precisa se reinventar para alcançar sua meta de transmitir e mediar o processo.

De acordo com Chartier (1991, p.184),

Para o historiador das sociedades de Antigo Regime, construir a noção de representação como o instrumento essencial da análise cultural é investir de uma pertinência operatória um dos conceitos centrais manuseados nestas sociedades. A operação de conhecimento está, assim, ligada ao utensílio nacional que os contemporâneos utilizavam para tornar sua própria sociedade menos opaca ao entendimento. Nas definições antigas (por exemplo, a do Dicionário universal de Furetière em sua edição de 1727) (23), as acepções correspondentes à palavra "representação "atestam duas famílias de sentido aparentemente contraditórias: por um lado, a representação faz ver uma ausência, o que supõe uma distinção clara entre o que representa e o que é representado; de outro, é a apresentação de uma presença, a apresentação pública de uma coisa ou de uma pessoa. Na primeira acepção, a representação é o instrumento de um conhecimento mediato que faz ver um objeto ausente substituindo-Ihe uma "imagem" capaz de repô-lo em memória e de "pintá-lo" tal como é. [...].

Os conceitos de Chartier (1991) sobre representação remetem a representação como elemento essencial de construção do saber, da criatividade, da confiabilidade da informação, da forma como o ser humano enxerga o mundo, como se vê representado nele e por ele, e como ocorre o processo de maturação do aprendizado e sua transformação em conhecimento, gerando novos conhecimentos, iniciando um ciclo continuo de representação.

A partir da concepção de Chartier (1991) e de Freire (1996; 2001), esse 
artigo tem como foco a representação e sua nova constituição no processo de ensino e aprendizagem nesse novo contexto da representação documental, da informação e do conhecimento. Assim, não será aprofundado aqui os diversos autores e suas concepções sobre a informação e conhecimento em suas mais abrangentes áreas do conhecimento.

\subsection{O Ensino nas Disciplinas das Áreas de REPRESENTAÇÃo da INFORMAÇÃo E Do Conhecimento Registrado nA UDESC.}

Desafios aceitos trazem oportunidades de (re)pensar as práticas e atitudes que o educador tem para com seu aprender a ser educador. Nesse desafio de (re)pensar, surgem novas oportunidades de (re)aprender, de se reinventar, de se renovar, recriar, e de lançar novos olhares aos novos horizontes que se despontam em nossas vistas.

Assim está sendo 2020 para todos os educadores (ensino fundamental, médio e superior), todos num mesmo processo de re(aprendizagem). Após um mês de aula, novos rumos foram tomados, novos projetos foram refeitos, novos planos repensados, novos desafios surgiram. Creio que o principal desafio é o da flexibilidade: ser flexível para "esvaziar sua taça" e se dispor a aprender e reaprender sempre. Muitas vezes, essa reaprendizagem está ancorada na nova geração digital, que utiliza e manipula as tecnologias como as gerações da década de 1970 utilizavam e manipulavam os brinquedos de sua época.

Nesse processo, retrato a realidade do Departamento de Biblioteconomia do Centro de Ciências Humanas e da Educação (FAED) da Universidade do Estado de Santa Catarina (UDESC). A UDESC interrompeu as aulas do semestre letivo 2020/1 no dia 17 de março de 2020, e retornou em maio com os cursos de pós-graduação e em junho com os cursos de graduação. Tem sido um constante aprendizado, um pensar e repensar de atividades, de novas práticas educativas, de métodos e didáticas a serem aplicadas agora de forma remota.

Durante o período em que as aulas foram suspensas, os docentes se mantiveram em constantes atividades remotamente, buscando encontrar soluções para o que, então, parecia um tempo curto, logo tudo retornaria. 
Se dividíssemos esse semestre em etapas, diria que o primeiro período foi o inicio de várias etapas. Quando a comunidade acadêmica e a sociedade compreenderam que não retornaria o semestre letivo presencialmente, iniciouse a segunda etapa: como seria realizado o ensino de forma remota, em que condições ele ocorreria, qual a infraestrutura que a universidade dispunha para oferecer aos docentes e acadêmicos, como seria o home office dos acadêmicos e docentes, em especial os que fazem parte do grupo de risco, e os acadêmicos em vulnerabilidade social.

Como construir uma nova realidade educacional, sem que houvesse prejuízo de ensino e aprendizagem? O Núcleo Estruturante Docente (NDE) se reuniu, com os departamentos e os diretores de centro, numa força tarefa para auxiliar os acadêmicos. Enquanto todos e todas trabalhavam para encontrar as melhores soluções, a sociedade cobrava uma postura da Universidade, criticando os docentes ("não querem trabalhar", "não estão dando aulas, tem tempo de sobra", como se não estivéssemos trabalhando), num total desrespeito ao corpo docente.

As reuniões departamentais com seus representantes discentes, o Centro Acadêmico de Biblioteconomia ( $C A B)$, juntos buscaram soluções. A Universidade se prontificou a fornecer computadores aos alunos em vulnerabilidade social e que fossem do grupo de risco, o que deixou muitos acadêmicos em vulnerabilidade sem equipamentos para aula, pois, ser do grupo de vulnerabilidade social não significa ser do grupo de risco (COVID19). Ofereceu também $R \$ 80,00$ para auxilio com a internet aos que não tem.

Foi aplicado um questionário com os acadêmicos da FAED, incluindo do curso de Biblioteconomia. Cada Departamento e NDE foi responsável pelo tratamento e análise dos dados. Novas legislações foram propostas.

O semestre iniciou em meio a incertezas, questões sem respostas, infraestrutura sendo ajustada durante o semestre em andamento, acadêmicos apavorados por não ter computador, ou não ter internet, ou não condições para trabalhar em home office.

Em meio a tudo isso, um ciclone atinge Santa Catarina, acadêmicos com casas alagadas, docentes também, quase duas semanas com alguns locais sem 
internet, mais incertezas, inseguranças, medos.

Aos poucos o semestre vai se configurando, e nessa nova configuração, vem a desistência de muitos acadêmicos: sem trabalho, bolsas, condições de se manterem em Florianópolis, voltam para casa dos pais, e muitos desistem de continuar os estudos.

Finalmente, chega o final do semestre, com as disciplinas finalizadas, exames finais realizados. Para compreender o semestre, foi realizado um pequeno questionário com os acadêmicos e docentes do Departamento de Biblioteconomia, mas que não reflete a opinião de todos, visto que o retorno não foi o esperado. Foram quatro perguntas dispostas no quadro 2.

\section{Quadro 2 - Questões enviadas aos docentes e discentes do Curso de Biblioteconomia}

\begin{tabular}{|c|c|c|c|c|}
\hline $\begin{array}{l}\text { 1. Como foi } \\
\text { semestre } \\
\text { você? }\end{array}$ & $\begin{array}{l}\text { esse } \\
\text { para }\end{array}$ & $\begin{array}{lr}\text { 2. Quais suas } \\
\text { dificuldades no } \\
\text { processo de } \\
\text { ensino } \\
\text { aprendizagem? }\end{array}$ & $\begin{array}{lr}\text { 3. Com relação as } \\
\text { disciplinas voltadas } \\
\text { para a área de } \\
\text { Organização } \\
\text { Recuperação da } \\
\text { Informação, quais as } \\
\text { vantagens } \\
\text { desvantagens com o } \\
\text { ensino remoto? }\end{array}$ & $\begin{array}{lrr}4 . \quad \text { Qual a } & \text { sua } \\
\text { perspectiva sobre } & \text { a } \\
\text { representação } & & \text { da } \\
\text { informação } & \text { e } & \text { do } \\
\text { conhecimento } & \text { nesses } \\
\text { tempos } & & \text { de } \\
\text { reaprendizagem? } & \end{array}$ \\
\hline
\end{tabular}

Fonte: Elaborado pela Autora (2020).

A seguir, será apresentado o retorno do questionário aplicado com os docentes e discentes.

Retorno dos docentes que aceitaram responder à questão 1: Como foi esse semestre para você?

Docente 1:

“Esse semestre não foi um semestre fácil por alguns fatores. O primeiro fator, é o contexto, saber que nessa pandemia, todo mundo fica numa posição muito vulnerável e isso causa um certo medo, um certo pavor, que nos acompanha no dia a dia, e interfere logicamente no nosso trabalho, nas nossas relações, né. Então foi uma situação bastante difícil. Além disso, o contexto todo da pandemia nos coloca essa situação de isolamento social e a gente fica sem possibilidade de sair de casa, a gente fica muito preso em casa, e isso também interfere demais, uma situação muito complicada também, o isolamento. Ainda foi um momento de muita adaptação porque as relações sociais e aí o trabalho, considerando o trabalho também, passou por um processo de, um processo forçado de virtualização, que nós tivemos que trabalhar sempre mediados por plataformas e com isso a gente perde muito o afeto, a relação social. Não perde, 
né, mas troca e querendo ou não, essa forma de relacionamento é fria, é mais é, ela nos deixa mais, ela não completa, não dá essa sensação de que a relação social se efetiva de fato, como acontece numa sala de aula presencial, ou como acontece numa conversa com os amigos presencial.".

\section{Docente 2:}

"Ele foi um semestre muito difícil, é, primeiro do ponto de vista técnico. Do ponto de vista técnico porque a gente teve que aprender fazendo, e fazendo oficialmente, por mais que a gente tenha tido algumas formações, é.. muitas das coisas que a gente tinha que usar ao longo do semestre pra fazê-lo funcionar minimamente bem, é.. a gente foi aprendendo fazendo e com muita dúvida, foi realmente muito difícil e além disso, emocionalmente difícil, então foi tecnicamente difícil, emocionalmente difícil por conta do próprio contexto nacional, mundial que a gente está vivendo de pandemia, mas também por conta das decisões atropeladas que foram tomadas pela administração central da universidade. Na verdade, me senti muito pressionada, me senti em outros momentos humilhada, por essa administração, e me agarrei nos alunos, sabe, no companheirismo dos colegas de departamento, especialmente que são os mais próximos e nos alunos, me dedicando ao máximo, mais, eu dei muito de mim, a ponto de não sobrar quase nada pra mim mesma, entende, mais eu acho que foi como uma fuga pra eu não olhar pra fora do que era nossa sala de aula nesse semestre, que era a tela do computador, então, foi muito difícil em todos os sentidos. E eu tive pequenos momentos de vitória sabe, quando eu conseguia dar uma aula bem dada, nessas condições, uma aula que eu sentia uma participação do alunos bem bacana, que dava um feedback bem legal né.. acho que é uma espécie de compensação para toda dificuldade, pra todo desgaste, físico e emocional.".

\section{Docente 3:}

"Pra mim na verdade, assim como pra ti, o semestre começou em maio já dando continuidade por conta da pós-graduação, foi bem complicado sobretudo pra mim, por conta de ter além das tarefas do ensino remoto, da adaptação desse ensino, da adaptação dos alunos, de tudo isso, alunos de graduação e de pós, né, que eu estava nas duas condições, ainda mais a questão da gestão, como coordenadora da pós, algumas questões também de gestão viraram remotas, foi bem complicado o semestre como um todo. Ai não estou falando só do ensino tá.”.

Retorno dos docentes que aceitaram responder à questão 2: Quais suas

\section{dificuldades no processo de ensino e aprendizagem?}

\section{Docente 1:}

"Foram muitas as dificuldades. A primeira é, trata-se da tradução dos conteúdos que foram pensados numa dinâmica presencial para esse contexto virtual. Em seguida a situação da infraestrutura técnica, que a gente não tem em casa né, a infraestrutura para ter uma boa qualidade no processo de ensino. Em terceiro lugar a questão da habilidade no processo para lidar com uma diversidade de 
recursos que vai desde a produção e a edição de vídeos, até mesmo na organização do design de uma plataforma como o Moodle, a mediação das discussões dentro de uma plataforma que requer o domínio de abrir microfone, fechar microfone, liberar vídeo, cuidar se essa liberação de vídeo de repente não está é, provocando uma lentidão pros outros alunos na internet, então tudo isso foi bastante complicado. Mas saindo dessa dimensão técnico, tecnológica, o que foi mais complicado foi lidar com os alunos, porque nós não temos nessa mediação da informação pela internet um feedback como no presencial, e, os alunos, os feedbacks que eles dão é, demonstram sempre um desânimo, uma desmotivação, então, eu precisei ter que me dedicar mais a um trabalho de conversa, motivação maior do que normalmente costumo fazer para que os alunos continuassem na disciplina, se dedicassem á disciplina. Então isso, foi uma situação bastante complicada, porque eu acho que questão da aprendizagem ficou bastante comprometida por conta dessas situações. Ainda com relação a essa questão, acho importante dizer que essa forma como estamos atuando, ela é, ineficiente, ela é insustentável, ela é prejudicial à saúde, a boa relação que o ensino requer, é porque há uma gama de fatores que o professor e o aluno precisam se preocupar além dos conteúdos relacionados a disciplina, como domínio técnico das ferramentas, como se a galera está me ouvindo, se os alunos conseguem responder a prova na plataforma, se vão conseguir responder o texto ali dentro de uma plataforma, então é, me parece que um ponto crítico nessa situação que nós estamos vivendo, foi a falta de apoio da universidade. Eu acho que as aulas deviam ter voltado, como voltaram, a distância, porque a gente não tem como controlar quanto tempo vai ser necessário o isolamento social, então talvez isso perdure por mais alguns meses, talvez até anos, lógico que isso numa perspectiva mais negativa e a gente não pode né, não formar o pessoal durante anos, esperando uma vacina ou acabar a crise pandêmica né, então acho que tinha que ter voltado, mas eu acho que a discussão ficou em torno muito de se volta ou não volta, então, as instituições, o governo pressionando para voltar, pela retomada, as instituições como sindicatos, associações gritando para não voltar que o ensino seria prejudicado, e o que não foi trabalhado, não houve uma articulação para cuidar de como seria essa retomada do ensino, me parece que se nós tivéssemos um técnico de informática atribuído a cada curso para auxiliar especificamente nas disciplinas, muitos dos problemas encontrados com facilidade. Muita insegurança dos alunos e dos professores que atrapalhou o processo de ensino e aprendizagem seria superado. Então me parece que faltou um pouco, pensar essa volta, me parece que seria papel nosso, enquanto docente empregado pela universidade. Lutar por essas condições né. Então fazer essa barganha: então voltamos se há uma necessidade de voltar como era colocado pela reitoria, nós voltamos, mas dentro de algumas condições. Acho que isso se perdeu no processo de negociação e sentimos no decorrer do semestre.".

\section{Docente 2:}

"Vou te falar de uma dificuldade bem geral que senti assim, que é de eu me convencer de que o que estava fazendo, era de fato, praticando o ensino, sabe, sendo pedagógica porque em muitos momentos eu tinha a impressão assim, de 
um grande fingimento, sabe, pra gente dá respostas internas e externas à universidade, a gente foi começando a coisa do jeito que foi, nos foi pedido, imposto, e as vezes, eu tinha uma sensação assim de que o que eu estava fazendo, apesar de ser o melhor que eu pude dar naquele momento, que isso tudo não ia alcançar é, o objetivo, porque eu ficava imaginando as dificuldades dos alunos do outro lado. Então assim, minha maior dificuldade no processo de ensino, eu acho que foi exatamente entender aquilo como um processo de ensino, é.. eu custei a acreditar que o que eu estava fazendo de fato era ensinar, tá, era ser professora.".

\section{Docente 3:}

"Eu já usava o Moodle antes, então acho que tive menos dificuldades do que alguns colegas, mas eu usava o Moodle mais como um assistente do ensino presencial. Então as aulas gravadas, as aulas virtuais, todo o processo acontecendo $100 \%$ na plataforma Moodle foi uma nova experiência e daí, eu tive um pouco de dificuldade de aprender, meio que urgentemente, como colocar esse ensino no Moodle. Por falar de questões tecnológicas, mas para além disso, eu também tive bastante dificuldade de entender que a gente não podia, não devia transportar o que se fazia no ensino presencial pro remoto. Por exemplo, eu ficava 3 horas conversando com os alunos em sala, numa aula presencial de 3 créditos, eu não podia ficar 3 horas falando com eles por uma tela de computador. Não é o mesmo nível de ensino, não é o mesmo nível de aprendizagem. Esse processo de ensino, de transformar uma coisa em outra, eu tive bastante dificuldade, ainda tenho, mais sobretudo no início, foi difícil mudar esse canal, porque eu sempre fui professora do ensino presencial, então tive dificuldade para me transferir, para esse mundo remoto $100 \% . "$.

Retorno dos docentes que aceitaram responder à questão 3: Com relação as disciplinas voltadas para a área de Organização e Recuperação da Informação, quais as vantagens e desvantagens com o ensino remoto?

\section{Docente 1:}

"Bom com relação as disciplinas voltadas a organização e recuperação, eu de fato não vejo vantagens, porque as vantagens seriam relacionadas as possibilidades de uso de ferramentas digitais remotamente. $E$ isso não me parece uma vantagem, dado que no contexto presencial, nós temos acesso a um laboratório de informática, onde podemos realizar as atividades no âmbito digital, então de fato, vantagem, eu não identifiquei vantagem. Acho que o formato remoto é bastante prejudicial a área de organização e recuperação da informação, sobretudo porque é uma área que ela teoricamente, é bastante densa e ao mesmo tempo, tecnicamente, ela é peculiar. $O$ aluno precisa aprender fazendo diversas, é.. diversos aspectos da disciplina, e o que eu identifiquei foi que trabalhar as especificações técnicas por exemplo de uma classificação como a CDD ou CDU é muito mais difícil no contexto remoto, porque o aluno não consegue manipular o documento físico né, não tem a CDD e CDU pra todo mundo, então os exercícios precisam ser um pouco mais 
superficiais, precisam ser um pouco menos problemáticos. Isso implica então no aprofundamento do conteúdo que foi prejudicado, isso implica também no processo de problematização, de elaboração, de busca de solução dos alunos. Então isso foi uma situação bastante complicada no contexto da organização e recuperação da informação, onde eu ministrei o conteúdo relativo a CDD e CDU. Ainda no contexto conceitual, falei agora no contexto prático dos exercícios, mais no contexto conceitual, me parece que esse cenário, ele do ensino remoto, ele também desestimula o aluno a em casa, ler um texto mais difícil, compreender uma ideia mais difícil. Quando essa leitura, ela é acompanhada de uma discussão, numa sala presencialmente, as dúvidas de um aluno, quando ele elabora essa dúvida e expressa na sala de aula, ela acaba se manifestando como duvida de um grupo, e aí, a gente consegue buscar soluções pras dúvidas e eu creio que esse movimento na sala de aula presencial, ele é mais propício ao contexto do ensino e aprendizagem e a gente não conseguiu reproduzir isso no contexto virtual porque nem todo aluno tem uma internet boa, tem muito aluno que tenta assistir aula ao vivo e não consegue, ele precisa assistir a gravação por $n$ fatores, que vão desde a questões pessoais, de trabalhos, de acesso aos recursos tecnológicos, então tudo isso interferiu demasiadamente no processo. Então, eu acho que é uma perda tanto da capacidade, da capacidade não, mas do processo do ensino e aprendizagem conceitual como também no âmbito técnico, prático.".

\section{Docente 2:}

"Eu não trabalhei as disciplinas dessa área nesse semestre, então vou ficar no campo da imaginação tá, eu imagino que deva ter sido muito complicado pros alunos especialmente, porque como eu falei, a gente vai dando tudo o que a gente tem, vai se adaptando, tem a parte muito prática da disciplina que o aluno também, que geralmente, quando a gente está no ensino presencial, a gente já isso como atividade complementar pra ser feita em casa, então eu acho que tem alguma coisa assim que no ensino remoto também deva ter sido mantida, mas eu tenho assim, pensado nos professores de catalogação, CDD e CDU, especificamente. Eu penso mais a $C D D$ e a catalogação, a representação descritiva I, que são os primeiros contatos que os alunos têm com a parte mais dura da Biblioteconomia, deve ser muito complicado. Fico imaginando os alunos interpretando o AACR e até ter a compreensão de um sistema de classificação porque assim, uma coisa é você estar em sala de aula, imaginou eu, você está olhando pros alunos, olhando nos olhos, você vê o quanto eles estão tentando prestar atenção, eu não sei como é essa recepção do outro lado, então eu imagino que ela tenha assim, uma certa vantagem de manter uma característica que é aquela parte da prática, dos exercícios que geralmente a gente passa que os alunos já fariam sozinhos, em casa ou talvez até, em conjunto com um colega de aula. $E$ as desvantagens ficam especialmente, eu imagino, naquelas disciplinas dessa área que introduzem a discussão, tipo a Temática I e a Descritiva I, eu acho que deve ser muito complicado por a gente não saber como é que está sendo essa recepção do outro lado.".

Docente 3: 
A questão das vantagens, eu vou dizer pelas vantagens que eu vi na minha disciplina de normalização, e que eu acho que é uma vantagem pra todos. E em alguns momentos, em alguns casos específicos, o fato da gente poder ter 0 assíncrono, as vezes é interessante, a gente no ensino presencial, as vezes está com alguma indisposição, está doente ou tem uma Banca, ou tem um Evento, e a gente precisa não estar presente, e nem sempre a gente consegue dar aulas assíncronas, a gente deixa atividades e tal, mas eu acho que esse facilitador do ensino remoto, ele nos ajuda nas questões assíncronas, mesmo no presencial, quando ele voltar, eu acho que ele nos ajuda. Mas em relação a desvantagem, sobretudo para a área de Organização e Recuperação da Informação que são bastantes práticas, a desvantagem é enorme por causa dessa praticidade, na Normalização também, disciplina que dei esse semestre, então está mais vívido pra mim, fazíamos muitos exercícios em sala com correção em sala, com eles utilizando a Norma, tirando dúvidas em sala e, isso não dá pra se aproveitar muito no remoto, porque a troca não acontece do mesmo jeito, os alunos também tem uma certa barreira com o remoto, inclusive pra usar as suas câmeras e tal, inclusive equipamentos que muitos não têm como deveriam, então eu acho que a perda pra área, é sobretudo, por conta de ser área basicamente prática, com uma práxis muito forte, então pra todas as disciplinas que tem essa premissa acho que há desvantagem sim.".

Retorno dos docentes que aceitaram responder à questão 4: Qual a sua

\section{perspectiva sobre a representação da informação e do conhecimento nesses tempos de reaprendizagem?}

\section{Docente 1:}

"A minha perspectiva é que a gente a gente vai precisar rever o perfil da disciplina, dado que o contexto remoto, ele impede da gente simplesmente traduzir a disciplina do presencial pro remoto. É necessário repensar e talvez até diminuir a carga horária destinada ao uso e aplicação da CDD e CDU e acrescentar mais uma discussão sobre as classificações no contexto digital, no contexto de taxionomia, digitais, de ontologias. Me parece que essa é uma tendência que foi evidenciada nesse contexto do ensino remoto porque o ensino de classificações mais tradicionais como CDD e CDU, implica no uso de instrumentos que normalmente é físico, dentro da nossa realidade, e os alunos sem esse acesso, não conseguem ter um processo de exercício, muito aprofundado. Então cabe a gente também, repensar o como vai investir tempo nesses exercícios que ficam impossíveis de realizar. Por isso uma possibilidade é justamente gastar um pouco mais do tempo da disciplina com outros contextos que são mais palatáveis a uma realidade remota.".

\section{Docente 2:}

"Eu acho, apesar de tudo, que dá pra pensar nisso, de forma positiva. Eu estou partindo muito do achismo. Mas eu acho que o termo reaprendizagem aí, foi muito bacana, porque é uma forma da gente reinterpretar a práxis, então como a parte de Organização, de Representação da Informação, ela vem sendo muito 
servida, vamos dizer assim, servida de novas possibilidades, a partir das tecnologias, especialmente das Tecnologias de Informação e Comunicação. Então talvez, dê pra aproveitar esse momento para incorporar ainda mais, toda essa oferta que é feita pra área de representação da informação e representação do conhecimento. Eu tenho um pouco essa visão, mais eu acho que a gente vai precisar, como é que eu vou dizer, não os bibliotecários em si, os alunos e os professores, mais acho que a população precisa estar um pouco mais, a gente, op povo, as pessoas do mundo precisam estar um pouco menos afetadas, eu não estou falando só do contágio, mas afetadas emocionalmente, pra gente dar esses passos. Eu tenho a impressão que nesse momento, as coisas estão começando a avançar lentamente porque, eu tenho cada vez mais percebido a importância do subjetivo, aquele que é de fato humano nas nossas tarefas diárias. Mas eu acho que tem potencial pra gente explorar muito a oferta tecnológica que é oferecida nessa área.

\section{Docente 3:}

"No meu entendimento, se muda um pouco a perspectiva do que seria a informação e o conhecimento nesse tempo de reaprendizagem. Eu acho que a informação e o conhecimento, a perspectiva, não muda, o que muda com certeza, os suportes dessa informação e conhecimento e daí da recuperação dessa informação e desse conhecimento. Aí com certeza, mas a representação deles como conceito, aí eu não consigo ver, pelo menos num primeiro momento, que tenha alguma diferença no momento, para o cenário que nós estamos vivendo atualmente.".

A abordagem apresentada por alguns docentes do Departamento não reflete o todo, visto que teve somente a aceitação de $20 \%$ que responderam ao questionário; no entanto, ficam claras as dificuldades enfrentadas no retorno às aulas, principalmente as dificuldades no processo de ensino e aprendizagem enfrentadas por esses docentes.

Com relação ao processo de repensar o ensino e a aprendizagem, compreende-se que os docentes estão passando por uma reflexão de sua atuação, do seu refazer e saber fazer, buscando a flexibilidade para buscar novas aprendizagens, novos conhecimentos, desmistificando aos poucos o uso das tecnologias como meios que proporcionam o ensino e a aprendizagem, mas que não dispensa o papel do docente como mediador desse processo.

As considerações de alguns discentes que se propuseram a responder ao questionário.

Retorno dos discentes que aceitaram responder à questão 1: Como foi esse semestre para você? 
Discente 1:

"Em relação ao semestre 2020/1, após o retorno via ensino remoto, ele se demostrou inicialmente caótico nas primeiras semanas, por conta da adaptação, tanto de discentes e docentes, com as plataformas e características dessa nova modalidade de ensino. Do meio para o fim do semestre, as atividades e ações remotas começaram a ser melhor trabalhadas, mas ainda havendo certa negatividade por conta da quantidade e prazo de trabalhos e atividades exigidas nas disciplinas.".

Discente 2:

"2/3 dele foi estressante e corrido. O final do semestre foi mais tranquilo que qualquer outro já tido anteriormente.”.

Discente 3:

"Este semestre foi muito cansativo, estressante, inevitavelmente incompleto e me deixou sobrecarregada.".

Discente 4:

"O semestre foi tranquilo. Sétima fase. Apenas 1 disciplina que foi muito bem conduzida pelo professor.".

Retorno dos discentes que aceitaram responder à questão 2: Quais suas dificuldades no processo de ensino e aprendizagem?

Discente 1:

“Organização e estruturação de cronograma pessoal para realização das atividades. Me considero de certa forma procrastinador no que tange certos trabalhos e atividades exigidas via ensino remoto.".

Discente 2:

"Muitos textos, prefiro aulas síncronas. Porém seria ideal que atividades fossem feitas durante essas aulas síncronas e não apenas conteúdo direito (estilo palestra) por períodos muito longos. Ou seja, tive dificuldade com grande número de leituras e com aulas síncronas demasiadamente longas e sem interação.".

Discente 3:

"As atividades online demandam muito mais tempo, deixam o aluno cheio de dúvidas por não estar vivenciando a aprendizagem ao lado do professor. São várias as dificuldades, entre elas os escassos recursos no ambiente domiciliar.".

Discente 4:

"Só teoria me faz perder o foco. Preciso ir fazendo mapa mental.".

Retorno dos discentes que aceitaram responder à questão 3: Com 


\section{relação as disciplinas voltadas para a área de Organização e Recuperação da Informação, quais as vantagens e desvantagens com o ensino remoto?}

Discente 1:

"Em relação as duas, pude notar dificuldades de colegas de questionar ou tirar dúvidas via ensino remoto, isso se deve muitas vezes a limitações técnicas ou da própria percepção de como a sua pergunta será recebida pela turma ou professor, algo que já era comum presencialmente. Em relação as vantagens, não tenho nada a comentar, talvez no máximo, nos fez utilizar e tornar mais prático algumas ferramentas que não utilizamos antes.".

Discente 2:

"Os problemas foram praticamente os mesmos citados acima, porém nas disciplinas mais práticas o uso de material digital facilitou, por conta que presencialmente não há marial para todos. Além de, no meu caso, ter notado um pouco mais da interação da turma por conta do uso do chat.".

\section{Discente 3:}

"A falta dos recursos disponíveis na UDESC vão causar uma lacuna no nosso aprendizado. Os professores tentam ao máximo auxiliar, mas o suporte tecnológico e as ferramentas disponíveis no meio acadêmico são insubstituíveis.".

\section{Discente 4:}

"Não acho que tenha vantagens. A conexão com a internet é instável. As disciplinas de tecnologias são um desafio para mim. É preciso ficar muito atenta ao que o professor diz. Quando estávamos em aula no laboratório de informática era possível acompanhar os exercícios juntamente com o professor. Atualmente temos que dividir a tela do computador em 2 partes para fazer este acompanhamento. Dificulta a atenção.".

Retorno dos discentes que aceitaram responder à questão 4: Qual a sua perspectiva sobre a representação da informação e do conhecimento nesses tempos de reaprendizagem?

\section{Discente 1:}

"Terão que ser bem trabalhadas com todos os discentes e docentes, pois o semestre 2020/02 virá logo, e com ele problemas surgirão. Principalmente de turmas iniciais ou que possuam dificuldades em relação as temáticas. O retorno presencial será o momento crucial para que os conhecimentos e experiências aprendidas ao longo da modalidade remota sejam postos em prática, assim analisando e avaliando a eficiência do processo interno.".

Discente 2: 
"Acredito que para quem está começando nesses conhecimentos seja algo bem complicado, pois acho que é mais complicado para os professores passarem a lógica e os alunos absorverem.".

Discente 3:

"Durante as disciplinas voltadas para a representação da informação e do conhecimento, utilizamos vários recursos técnicos, que fora do ambiente acadêmico não dispomos, acredito que, apesar dos esforços da professora responsável, o processo será mais moroso e que será inviável absorver toda a informação que a disciplina abrange, deixando uma lacuna no aprendizado.".

Discente 4:

"As disciplinas que necessitam utilizar o AACR2, CDU e CDD são um grande desafio. Os alunos precisam utilizar o material do departamento de Biblioteconomia. Pode-se utilizar uma CDD que não é completa mas pode ajudar e que está disponível online ( $h$ ttp://bilica.org.br/sistema/modulos/ acervo/cdd.php). O MARC 21 também é desafiador pois são utilizados em disciplinas em que o contato com o professor é imprescindível. Os alunos têm muitas dúvidas e precisam do auxílio do professor e do monitor. Dependendo da quantidade de alunos na sala será necessário dividir a turma em 2.".

Mesmo o retorno dos discentes não sendo representativo, num total de aproximadamente 130 alunos no curso de graduação, a entrevista daqueles que responderam foram consideradas nesse artigo, pois dos respondentes, dois alunos representam o $\mathrm{CAB}$, e duas alunas estão concluindo o curso. Pela baixa adesão dos alunos em responder a quatro questões, verifica-se como foi difícil o acesso a esses acadêmicos, conforme afirmado pelos docentes participantes da pesquisa.

As dificuldades apresentadas pelos acadêmicos durante o semestre e no que diz respeito ao ensino e aprendizagem, a maioria dos respondentes relatou que foi cansativo, estressante, com muitas atividades que se sentiram sobrecarregados. Somente um respondente, por estar na sétima fase e já ter concluído a maioria das disciplinas antecipadas, disse ter sido um semestre tranquilo. Os respondentes também concordaram com os docentes nos quesitos falta de interação, dificuldades com as plataformas, excesso de atividades.

Quanto às desvantagens, os acadêmicos apontaram também a dificuldade de interação, dos colegas fazerem questões sobre as disciplinas, a falta de recursos e apoio cedidos pela UDESC, conexão da rede internet instável, 
dificuldade de atenção por meio remoto, dificuldade de não ter o professor auxiliando no momento de realizar as atividades como em sala de aula. Como vantagem foi apresentado a interação entre uma turma por conta do uso do chat.

Sobre a perspectiva da pergunta 4 , os discentes respondentes já estão vislumbrando que devem ser bem trabalhadas, ou seja, bem preparada para 0 próximo semestre, se preocuparam com os colegas que ainda não cursaram essas disciplinas. Devido ao impacto das atividades práticas das disciolinas dessa área, um respondente enfatizou que ficou uma lacuna em seu processo de aprendizagem relacionado a ela. Outro respondente aborda a dificuldade com os instrumentos utilizados nas disciplinas, que não estão disponíveis online, e também a necessidade do auxílio do professor e monitor em disciplinas práticas, muitas vezes, devido ao número de alunos, há a necessidade de divisão de turma, uma realidade do ensino presencial. E torcem que a aula presencial retorne logo.

\section{CONCLUSÃO}

Confesso que aceitar o desafio de abordar um tema que estivesse de acordo com o Tema proposto para o Dossiê desse importante periódico me fez, muitas vezes, perder o foco dentro de um tema tão complexo: "Perspectivas para a Representação Documental em Tempos de Reaprendizagem".

Assim, ao pensar nas perspectivas da representação documental e reaprendizagem, analisando o momento atual que trouxe tantas mudanças, o desafio foi discorrer sobre a realidade da prática do ensino e da aprendizagem na grande área de Organização e Representação da Informação.

Para essa autora, a perspectiva do processo de ensino e aprendizagem, não somente na área de Organização e Representação da Informação e do Conhecimento, mas em todas as áreas do conhecimento, deve partir do princípio que tanto o educando quanto o educador são aprendizes desse processo. Que não há metodologia, tecnologia, didática que seja suficiente para enfrentar os novos desafios impostos pelo contexto atual ou pelos que ainda poderão vir, se não tivermos flexibilidade, empatia e respeito mútuo. 
Nesse semestre, tive particularmente que me reinventar, como todo colega docente, em todos os níveis de ensino em nosso país. Não sou "super heroína", não sou a melhor docente, mas procuro aprender com meus alunos, na troca, no compartilhamento e na auto ajuda. Recebi compreensão em períodos críticos esse semestre por parte dos meus alunos, e, também procurei compreender a cada um. Procurar ver o ser humano que vai além do papel do aluno, do seu fazer diário, das suas obrigações como acadêmicos, nos coloca em posição de parceria, de companheirismo que resulta no respeito mútuo.

Quando digo que sou "Freiriana", estou me referindo ao processo de ensino e aprendizagem construído por Paulo Freire, em que coloca o docente e o discente lado a lado, num processo cíclico e ininterrupto de criação e transformação. Só assim, podemos um dia ter uma sociedade educada e igualitária.

\section{AGRADECIMENTOS.}

Aos Docentes e Discentes que aceitaram fazer parte desta pesquisa, a minha eterna Gratidão.

\section{REFERÊNCIAS}

ALMEIDA, M. E. B. de. Educação a distância na internet: abordagens e contribuições dos ambientes digitais de aprendizagem. Educação e Pesquisa, São Paulo, v.29, n.2, p. 327-340, jul./dez. 2003

ARRUDA, S. M. de; CHAGAS, J. Glossário de biblioteconomia e ciências afins: português-inglês. Florianópolis: Cidade Futura, 2002.

BRUZZI, D. G. Uso da tecnologia na educação, da história à realidade atual. Polyphonía, v. 27/1, jan./ jun. 2016.

CHARTIER, R. O mundo como representação. Estudos Avançados, v. 11, n. 5, 1991. Disponível em:

https://www.scielo.br/scielo.php?script=sci_arttext\&pid=S010340141991000100010. Acesso em: 01 de outubro de 2020.

FREIRE, P. Carta de Paulo Freire aos professores: ensinar aprender: leitura do mundo, leitura da palavra. Estudos Avançados, v. 15, n. 42, 2001. 
FREIRE, P. Pedagogia da autonomia: saberes necessários a prática educativa. 25.ed. São Paulo: Paz e Terra, 1996.

LARA, M. L. G. de. Linguagens documentárias, instrumentos de mediação e comunicação. R. bras. Bibilotecon. e Doc., São Paulo, v. 26, n. 1/2, p. 72-80, jan./jun., 1993. Disponível em:

https://rbbd.febab.org.br/rbbd/article/view/396/370. Acesso em 30 de agosto de 2020.

PEREIRA, A. M. A educação continuada a distância do catalogador. 2000. Dissertação (Mestrado) - Faculdade de Filosofia e Ciências. Universidade Estadual Paulista/UNESP. Marilia, 2000.

VALLEJO, A. P. Novos cenários educativos. In: VALLEJO, A. P.; ZWIEREWICZ, M (orgs). Sociedade da informação, educação digital e inclusão. Florianópolis (SC): Insular, 2007. p.13-52.

\title{
RETHINKING ABOUT THE TEACHING AND LEARNING PROCESS IN THE REPRESENTATION OF INFORMATION AND KNOWLEDGE
}

\begin{abstract}
Introduction: The following article aims to rethink the teaching and learning process in the representation of information and knowledge in times of relearning. Objective: The objective is to identify how information and knowledge representation occurs in the process of teaching and learning. Methodology Methodologically this is a qualitative, descriptive, and bibliographic survey research. The data collection was accomplished through a questionnaire that was sent through WhatsApp to professors and students of the Course Library and Information Management from UDESC (Universidade Do Estado de Santa Catarina), a University from the State of Santa Catarina in Brazil. The questionnaire was answered in writing by some and by voice audio recording by others, as well as by e-mail by one respondent. The data treatment was accomplished by the transcription of the interviews to audio, forwarded to the interviewed ones for conference and authorization for publication. Results: And lastly, the data analysis was performed by subject categorization and content analysis. As a result, it's understood that the return of the questionnaires was not representative of the demand of teachers and students in Course, despite that it's considered that they reflect the current moment of education in Brazil. Conclusions: In conclusion, it was identified that teachers and students are working together in this new format of remote teaching and are sharing the difficulties with technologies. Therefore, with the teaching and learning model that is being rethought, teachers and students are relearning together.
\end{abstract}

Descriptors: Representation of information. Knowledge representation. Teaching and 
learning. Relearning.

\title{
(RE) PENSAR LA ENSEÑANZA Y APRENDIZAJE DE REPRESENTACIÓN DE INFORMACIÓN Y CONOCIMIENTO
}

\begin{abstract}
RESUMEN
Introducción: Este artículo tiene como objetivo (re) pensar la enseñanza y el aprendizaje de la información y la representación del conocimiento en tiempos de reaprendizaje. Objetivo: Identificar cómo ocurre la enseñanza y el aprendizaje de la información y la representación del conocimiento. Metodología: la investigación realizada es de enfoque cualitativo, descriptivo, del tipo encuesta bibliográfica. Para la recolección de datos, se envió un cuestionario a los profesores y estudiantes del curso de Bibliotecología y Gestión de la Información de la UDESC a través de grupos de WhatsApp. El cuestionario fue respondido por escrito por algunos y mediante grabación de voz por otros encuestados, así como por correo electrónico por un encuestado. Para el tratamiento de los datos se realizó la transcripción de las entrevistas por audio, remitida a los entrevistados para conferencia y autorización para publicación. Para el análisis de datos, se realizó una categorización por tema y análisis de contenido. Resultados: Como resultado, se entiende que la devolución de los cuestionarios no fue representativa de la demanda de los docentes y estudiantes del Curso, sin embargo, se considera que reflejan el momento actual de la educación en Brasil. Conclusiones: como conclusión, se identificó que docentes y estudiantes están trabajando juntos en este nuevo formato de enseñanza a distancia, compartiendo las dificultades con las tecnologías, y con el modelo de enseñanza y aprendizaje que se está repensando, reaprendiendo juntos.
\end{abstract}

Descriptores: Representación de información. Representación del conocimiento. Enseñanza y aprendizaje. Recuperación.

Recebido em: 15/09/2020

Aceito em: 30/09/2020 